\title{
The Influence of Somatotype, Strength and Flexibility on Injury Occurrence among Female Competitive Olympic Style Gymnasts -A Pilot Study
}

Karen J. Wright, BSc, Carl De Crée, MD, MA, MPESportsMed, MSc.

Physiology of Exercise Unit, School of Physical Education, Sport and Leisure, De Montfort University, Bedford, MK40 2BZ, United Kingdom

\begin{abstract}
Objectives - A pilot project to investigate somatotype, strength and flexibility as risk factors for injury amongst female competitive gymnasts. Methods-Fifteen subjects (ranging in age from 8 to 18 years) volunteered to participate in the present study. An ex-post facto study design using independent samples was employed. Injury history was established through use of a questionnaire. From this information, each individual's injury status was categorised as either "high" or "low" using a previously designed and validated scoring system. Somatotype ratings were determined, followed by a battery of tests to assess muscular endurance and strength, and flexibility. Results-A multivariate analysis of variance (MANOVA) revealed that there was no significant difference between groups of low and high injury rates and the dependent variables selected. However, univariate analysis suggested trends indicating that the low injury subjects were more flexible (back extension \& ankle dorsiflexion) than those who had reported more injuries (both $\mathrm{P}=0.013$ ). Independent $\mathrm{t}$-tests revealed that between groups of low and high injury rates there were significant differences in age $(\mathrm{P}=0.002)$, stature $(\mathrm{P}=0.006)$, body mass $(\mathrm{P}=0.001)$, and years of gymnastics training $(\mathrm{P}=0.016)$. Conclusions - In the present study, strength and somatotype proved not to be good indicators of an individual's susceptibility to injury. However, there were trends suggesting that low levels of flexibility may predispose a gymnast to injury. The incidence of injury may also be related to the number of years an individual has participated in competitive gymnastics. In addition, older, taller and heavier gymnasts may be at greater risk of incurring injuries. It is concluded that training methods should be adapted to suit the needs of each individual, depending on their age, stature and body mass. It is also recommended that coaches become aware of which individuals may be more predisposed to injury by carrying out a physical assessment prior to participation.
\end{abstract}

Key words: gymnastics, injuries, prevention

(This article was submitted Oct. 1, 1998, and was accepted Dec. 1, 1998)

\section{INTRODUCTION}

Over the past two decades the sport of gymnastics has experienced a popularity explosion. According to the British Amateur Gymnastic Association (BAGA) in the United Kingdom alone, approximately 4 million people participate in 10,000 gymnastics clubs around the country; $75 \%$ of these gymnasts are female ${ }^{20)}$. The Féderation Internationale de Gymnastique (FIG), which sets the standard of judging for elite level gymnasts, revises the official judging code every four years. This, in effect, continually increases the criteria 
which every gymnast must adhere to. Because of these demands a particular level of difficulty is attained at an age younger than ever before. Consequently, intensive training occurs during the most vulnerable stages of physical development ${ }^{17}$. The intensity of training in terms of number of hours spent in the gym per training session is also increasing, which in turn increases a gymnast's exposure to injury ${ }^{14)}$. Kerr ${ }^{8)}$ recognised a growing trend in gymnastic injuries amongst female competitors in particular. Because of the complex nature of the movements performed in gymnastics, a high level of stress is placed on the muscles, tendons and joint structures of the body and this to a greater extent than in most other sports ${ }^{18)}$. The above-mentioned reasons justify an increasing interest in the prevention of sports injuries in gymnasts. Research suggests that deficits in strength and flexibility are risk factors for athletic

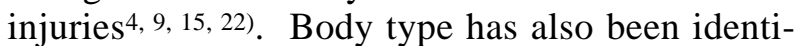
fied as a contributing factor to injury ${ }^{16,21)}$.

The purpose of the present pilot study is to examine differences in strength, flexibility and body type between groups of competitive female gymnasts with low and high rates of injuries. The outcome may be helpful in designing larger scale studies with prospective design, which could in a more definitive way identify if the chosen variables are significant risk factors or predictors of injury. However, even the information gained from this pilot study may already aid injury prevention strategies and may have implications for coaches in the selection and training of future elite gymnasts.

\section{METHODS}

\section{Subjects}

The subjects $(\mathrm{N}=15)$ were all members of the Kettering Olympic Gymnastic Club Elite Competition Squad, Kettering, Northamptonshire, UK. They ranged in age from 8 to 18 years (mean \pm $\mathrm{SD}, 11.8 \pm 3.5 \mathrm{yrs}$ ) and trained between 9 and 21 hours per week (13.6 $\pm 5.8 \mathrm{hrs})$. All subjects gave their informed written consent, and the study was carried out according to the guidelines of the Declaration of Helsinki. Subjects were tested during the competition season over a period of 4 weeks, at the same venue and time each week. The postmenarcheal subjects $(\mathrm{N}=5)$ by history were having regular menstrual cycles (24-35 days in length) and did not take oral contraceptives. These subjects were tested within the luteal phase of the menstrual cycle to standardise any potential differences in strength, flexibility and anthropometric measurements. A questionnaire, adapted from Feehan and Waller ${ }^{3}$ ) was used to gather personal data and details of injuries sustained during the previous 4 years. For the purpose of this study, an injury was defined as "a gymnastics-related incident that limited participation in any of the gymnastic events". Injuries were classified by the scoring system described previously ${ }^{20}$. In brief, this system allows a score to be assigned to each injury incurred depending on the severity of the injury and the number of days training had to be interrupted. According to their scores, individuals were then classified as having a "low" $(\mathrm{N}=8)$ or "high" $(\mathrm{N}=7)$ injury status.

\section{Testing Protocol}

The subjects' somatotypes were determined using the Heath-Carter somatotype method, which categorizes each individual into three possible body types: endomorph, mesomorph, or ectomorph. Percentage body fat was estimated from 4 subcutaneous skinfolds (triceps, subscapular, suprailiac, medial calf) using Siri's equation for percentage body fat. Skinfolds were measured by a Holtain skinfold caliper (Holtain Ltd., Crosswell, Crymych, Dyfed, UK). Anthropometric data included height, mass, 2 muscle girths (biceps, medial calf) and 2 bone widths (humerus, femur). Strength was assessed through the use of 2 general strength tests (grip strength and standing vertical jump) and by 2 tests of muscular endurance (pullups and push-ups). Grip strength was determined according to Johnson and Nelson' ${ }^{6}$, using a hand held grip dynamometer adjusted for individual hand size (Takeikiki Kogyo Co. Ltd., Tokyo, Japan). The vertical jump (using the chalk jump method) and the pull-up/push-up test were performed as previously described by Clarke1). Flexibility was determined for the shoulder and wrist, ankle, back and hamstring areas, using procedures explained in detail before ${ }^{6}$. All flexibility tests were carried out after a 30-min general warm-up.

\section{Data Analysis}

Differences in strength and flexibility between the low and high injury groups were assessed by multivariate analysis of variance (MANOVA). 
The relationship between somatotype and injury occurrence was explored using the chi-square test. Differences in anthropometric variables and injury scores were analyzed by means of an independent samples t-test. When the risk of committing a Type II error may exceed that of Type I errors often so with small sample sizes - a less rigorous $\alpha$-level may be appropriate. Therefore, in this study, results were considered significant at the $90 \%$ confidence level.

\section{RESULTS}

\section{Injury Distribution}

The high injury group was significantly older $(\mathrm{P}=0.002)$, taller $(\mathrm{P}=0.006)$, heavier $(\mathrm{P}=0.001)$. Although, the percentage of body fat was not significantly different between the two groups, there was a significant difference in BMI $(\mathrm{P}=0.001)$, with the high injury group being marginally "underweight", and the low injury group falling within the lowest category, labeled for adults as "severe protein-energy malnutrition". Both groups were observed to have the same dominance of mesomorphy followed by ectomorphy (Table 1). The high injury group had participated in gymnastics for significantly longer than the low injury group $(\mathrm{P}=0.016)$.

A total number of 7 injuries was incurred by the low injury group, giving an injury rate of 0.9 per gymnast $(0.3 / 1000 \mathrm{hrs})$. However, 2 out of the 8 gymnasts did not experience any injuries. In comparison, the high injury rate group reported a total of 27 injuries at a rate of 3.9 injuries per gymnast (1.8/1000 hrs).

\section{Injury and Strength}

There were no significant differences between the strength capabilities of the low and high injury group. On closer inspection of the data trends were observed $(\mathrm{P}=0.021)$ suggesting that the high injury group scored better on the vertical jump than the low injury group.

\section{Injury and Flexibility}

MANOVA did not reveal any significant differences between flexibility capabilities of the low and high injury rate group. However, univariate analyses indicated that the low injury rate group scored better on back extension in bridge $(\mathrm{P}=0.013)$ and ankle dorsi-flexion $(\mathrm{P}=0.013$; Table 2$)$.
Table 1. Comparison of gymnasts with low $(\mathrm{N}=8)$ and high $(\mathrm{N}=7)$ injury status on selected anthropometric measures. Data are means \pm SD

\begin{tabular}{lcc}
\hline \multicolumn{1}{c}{ Item } & Low Injury & \multicolumn{1}{c}{ High Injury } \\
\hline Age $(\mathrm{yrs})$ & $9.5 \pm 1.3^{*}$ & $14.3 \pm 3.3^{*}$ \\
Stature $(\mathrm{cm})$ & $132.5 \pm 6.8^{*}$ & $153.9 \pm 17.3^{*}$ \\
Mass $(\mathrm{kg})$ & $28.0 \pm 4.3^{*}$ & $48.0 \pm 12.8^{*}$ \\
BMI & $15.8 \pm 1.3^{*}$ & $1.5 \pm 0.5$ \\
Endomorphy & $19.8 \pm 2.5^{*}$ & $2.0 \pm 0.6$ \\
Mesomorphy & $4.0 \pm 0.3$ & $3.3 \pm 0.9$ \\
Ectomorphy & $3.4 \pm 0.7$ & $2.9 \pm 0.9$ \\
Body Fat $(\%) \dagger$ & $19.4 \pm 2.6$ & $22.4 \pm 3.3$ \\
Average Injury Score & $2.9 \pm 2.6^{*} \ddagger$ & $19.1 \pm 8.8^{*} \neq$ \\
\hline
\end{tabular}

$*$ Significance $\mathrm{P}<0.05$. $\dagger$ Estimated from sum of four skinfolds (2). $\$$ Groups were defined on the basis of the rate of injuries.

\section{Injury and Body Type}

Out of the 15 subjects tested, $66.7 \%$ were ectomesomorphs. Three subjects were meso-ectomorphs and the remaining 2 subjects were balanced mesomorph-ectomorphs (see Table 3). By categorising the frequency of body types across injury status it was observed that there was an equal distribution of the dominant body type for both low and high injury status groups.

\section{Types and Location of Injuries}

Table 4 provides an overview of the types of injuries incurred. The range of the injuries by far was dominated by sprains and strains, and the two together accounted for approximately $50 \%$ of the injuries in either the low or high injury group. The percentage of acute injuries in the low injury group was 88 , as opposed to 70.4 in the high injury group. The number of overuse injuries was significantly higher in the high injury group than in the low injury group $(29.0$ vs. $11.1 \%)$. As to the specific sites of injuries, the lower extremity, in particular the ankle was affected in $50 \%$ of all cases. The lower back was the second most commonly injured site $(13.8 \%)$ with the toes as a close runner up (11.1\%). No association between types of injuries and the factors age, height, strength, or flexibility, was identified. However, there was a clear association between the instrument and the number of injuries, with, in the low injury group, the beam alone accounting for almost three quarters of all injuries. In the high injury group, the beam was still responsible for the highest proportion of the injuries (28\%), immediately followed 
Table 2. Comparison of gymnasts with low $(\mathrm{N}=8)$ and high $(\mathrm{N}=7)$ injury status on selected strength and flexibility measures. Results are means $\pm \mathrm{SD}$

\begin{tabular}{lcc}
\hline \multicolumn{1}{c}{ Item } & Low Injury & High Injury \\
\hline Strength & & \\
Sargent Jump (cm) & $37.6 \pm 7.4^{*}$ & $45.7 \pm 3.8^{*}$ \\
Grip Strength (N/kg) & $5.9 \pm 0.9$ & $5.9 \pm 0.9$ \\
Pull Up: Push Up (Absolute score: PI $\dagger)$ & $0.4 \pm 0.2$ & $0.3 \pm 0.2$ \\
Flexibility & & \\
Sit and Reach (cm) & $31.8 \pm 2.7$ & $31.6 \pm 3.5$ \\
Shoulder and Wrist Elevation $\ddagger(\mathrm{cm})$ & $25.7 \pm 10.5$ & $31.9 \pm 14.0$ \\
Back Extension in Bridge $\ddagger(\mathrm{cm})$ & $22.6 \pm 1.9^{*}$ & $25.3 \pm 4.9^{*}$ \\
Ankle Dorsi-flexion $¥(\mathrm{~cm})$ & $62.3 \pm 8.0^{*}$ & $75.9 \pm 10.3^{*}$ \\
Ankle Plantar-flexion $¥(\mathrm{~cm})$ & $2.0 \pm 1.7$ & $1.8 \pm 0.9$ \\
\hline
\end{tabular}

*Levels of significance $\mathrm{P}<0.05$. †Ponderal Index. $\$$ Lower score=better performance (according to ref. 6).

Table 3. Distribution of somatotypes across low $(\mathrm{N}=$ 8) and high injury $(\mathrm{N}=7)$ status groups

\begin{tabular}{lcc}
\hline \multicolumn{1}{c}{ Somatotype } & Low Injury & High Injury \\
\hline Ecto-Mesomorph & 5 & 5 \\
Meso-Ectomorph & 2 & 1 \\
Mesomorph-Ectomorph & 1 & 1 \\
Total & 8 & 7 \\
\hline
\end{tabular}

by the vault $(20 \%)$ and the floor $(16 \%)$. When both groups where considered together, the beam accounted for $40 \%$ of the injuries, followed by the bars, vault and floor (each 15\%).

\section{DISCUSSION}

Some of our data are derived from a retrospective research design. It is recognised that results may have been confounded to some extent by previous injuries. The athlete may have recovered from a past injury which may not presently affect performance but may have resulted in an alteration of physical characteristics such as strength and flexibility. In addition, our trial design is not free of the often typical problems associated with retrospective studies. These problems have been explained in detail elsewhere ${ }^{7)}$, and mainly have to do with the somewhat unreliability of the data depending on individual's personal account. The above-mentioned problems as well as the limited size and thus possibly above normal homogeneity of the present sample (all subjects stem from the same club), represent confounding variables. How-
Table 4. Injury type distribution among high $(\mathrm{N}=7)$ and low injury groups $(\mathrm{N}=8)$

\begin{tabular}{lcc}
\hline Injury type & Low injury $(\%)$ & High injury $(\%)$ \\
\hline Sprain & 28.6 & 25.9 \\
Strain & 28.6 & 22.2 \\
Fracture & - & $18.6^{*}$ \\
Abrasion & $42.8^{*}$ & $3.7^{*}$ \\
Elongation & - & $11.1^{*}$ \\
Contusion & - & 7.4 \\
Growth plate & - & 3.7 \\
Other & - & 7.4 \\
\hline Total & 100 & 100 \\
\hline
\end{tabular}

*Significantly different at $\mathrm{P}<0.05$.

ever, the retrospective approach is extremely cost effective and can provide an indication of potential risk factors.

In the present study, the majority of the injuries reported were acute in nature. Various other authors $10,11,21)$ have also found a dominance of acute injuries in studying elite female gymnasts. Consistent with the finding of this study, many researchers have found that in gymnasts the ankle is extremely vulnerable to injury ${ }^{11,16,17)}$. It was found in the present study that approximately $20 \%$ of the injuries were caused by dismounting or repetitive heavy landings; these may contribute to the high incidence of ankle injuries found. From this information, it can be argued that the quality of the landing mats used should be considered carefully in order that injuries such as these are reduced or prevented completely. In addition, attention 
new strategies to prevent injuries should especially focus on exercises involving the beam, which largely appears to be the most dangerous apparatus.

It has been stated before ${ }^{1)}$ that the pre-pubertal physique is favourable and advantages the strength to weight ratio. From this assumption it was expected that the low injury group would perform better on the pull-up/push-up test as the gymnasts in this group were significantly younger, lighter and shorter. However, in this study, strength did not prove to be a significant factor in the prediction of injury risk. This may be because the two groups train for a similar number of hours per week, and because they follow similar training programmes in terms of strength training. Inter-individual differences in strength across low and high injury groups appeared to depend on which strength test was being performed. Although, group comparisons in strength thus did not reach significance, there were trends suggesting that the high injury group scored better on tests of absolute strength and power as in the vertical jump and grip strength; conversely, the low injury group performed better on the pull-up/push-up test. However, one should bear in mind that this test relies heavily on a high strength to weight ratio. Taking into account that this study merely represented a pilot project, no definite conclusions are aimed for. Similar smallscale studies do offer useful information, though, that may assist in better designing later, more extensive studies which ideally would need to have a prospective design.

There were also trends indicating that people with less flexibility are more likely to have injuries. These results suggest that a lower level of flexibility may contribute to injury risk. Many researchers suggest that deficits in flexibility can contribute to a greater occurrence of injury. However, the evidence is again unclear. Maffulli et $a l .{ }^{15)}$ found that flexibility did not exert a significant role in injury occurrence. Similarly, Steele and White ${ }^{21)}$ also failed to prove a relationship between deficits in flexibility in gymnastics and injury proneness. Nevertheless, the aforementioned authors 15,21$)$ suggest that comparatively high or low levels of flexibility can increase an individual's susceptibility to injury. Similarly, Meeusen and Borms ${ }^{16}$ ) suggest that the stiffening of tendons around the joint and the accompanying decrease in flexibility can increase the risk of in- jury. The trends in the present study may indicate that it is the less flexible individuals who are more likely to sustain injuries.

By categorising the frequency of body types across injury status, it was observed that there was an equal distribution of the dominant body types for both low and high injury groups. This suggests that, in the present study, somatotype is not a good indicator of injury risk. This is in agreement with previous studies ${ }^{5,12)}$ which found that anthropometric characteristics had little influence on injury occurrence. In the present study, somatotype ratings do not indicate whether an individual is more or less likely to incur and injury. Also, it was observed that the high injury group were significantly older, taller, and heavier. It has been suggested that these factors alone can significantly increase an individual's predisposition to injury ${ }^{19)}$. Similarly, Taimela et al. ${ }^{22}$ ) argue that tall and relatively heavy gymnasts are predisposed to injury. This is supported by other authors ${ }^{14,21)}$ who found that the physical characteristics of the gymnast play a major role in injury proneness.

There were no significant differences between the groups in terms of hours of training per week. However, the high injury group had been participating in the sport for significantly longer time than the low injury group. Thus in effect, the high injury group has had a more prolonged exposure to the sport, and consequently may suffer more injuries as a result. This suggestion is supported by Steele and White ${ }^{21)}$ who state that the number of years participating in the sport is a significant factor in the prediction of injury risk.

It is apparent that there is a multitude of factors which may contribute to injury risk within the same risk group even when scoring similar results in the tests performed. In conclusion, the results of the present study teach us that flexibility in particular may affect injury risk among competitive female gymnasts. It is also observed that variables such as age, stature, body mass and number of years in the sport may provide more information about an individual's predisposition to injury rather than strength or somatotype rating. It might be useful to develop a form of physical assessment which prior to participation detects factors that predispose an individual to injury. An awareness of injury predisposition prior to the onset of intensive training may prevent the injury from occurring. Furthermore, it is particularly important that the 
coach that athletes who have sustained previous injuries may be at a greater risk of injury. Children, especially those who are participating at the highest levels, deserve special consideration so that permanent damage is avoided. As intensive training of young athletes increases, so will the number of injuries incurred. A (perhaps utopian) decommercialization of the Olympics and the introduction of an age limit would prevent the exploitation of children by excessive training routines, and possibly reducing risk taking. We feel that the data of the present pilot study may produce a useful basis for larger prospective studies in order to generate conclusions with a wider applicability in order to further identify the factors which may predispose young individuals to injury.

\section{REFERENCES}

1) Clarke HH: Application of Measurement to Health and Physical Education, 5th ed. Englewood-Cliffs, London. Prentice-Hall Publications, 1967.

2) Durnin JV, et al: The assessment of the amount of fat in the human body from measurements of skinfold thickness. Br J Nutr 21: 681-689, 1967.

3) Feehan M, et al: Precompetition injury and subsequent tournament performance in full-contact taekwondo. Br J Sports Med 29: 258-262, 1995.

4) Grisogono V: Children and Sport - Fitness, Injuries and Diet. London, John Murray Publishers, 1991.

5) Jackson DW, et al: Injury prediction in the young athlete: A preliminary report. Am J Sports Med 6: 614, 1978.

6) Johnson BL, et al: Practical Measurements for Evaluation in Physical Education. USA, Burgess Publishing, 1986.

7) Judd CM, et al: Research methods in social relations (6th ed.). Holt, Rhinehart \& Winston Publ., Fort Worth, Dallas, TX, 1991.
8) Kerr G: Preventing gymnastic injuries. (editorial) Can J Sport Sci 15: 227, 1990.

9) Knapik JJ, et al: Strength, flexibility and athletic injuries. Sports Med 14: 277-288, 1992.

10) Kolt GS, et al: Epidemiology of injury in australian female gymnasts. Sports Med, Training and Rehab 6: 223-231, 1995.

11) Lindner KJ, et al: Injury patterns of female competitive club gymnasts. Can J Sport Sci 15: 254-261, 1989.

12) Lysens R, et al: The predictability of sports injuries. Sports Med 1: 6-11, 1984.

13) Mackie SJ, et al: Injuries in female gymnasts. Phys Sportsmed 22: 40-45, 1994.

14) Maffulli N: Intensive training in young athletes: An orthopaedic surgeon's viewpoint. Sports Med 9: 229_ 243, 1990.

15) Maffulli N, et al: Training in elite young athletes (the training of young athletes (TOYA) study): Injuries flexibility and isometric strength. Br J Sports Med 28: 123-136, 1994.

16) Meeusen R, et al: Gymnastic injuries. Sports Med 13: 337-356, 1992.

17) Nattiv A., et al: Injuries and special concerns in female gymnasts. Phys Sportsmed 21: 66-82, 1993.

18) Nelson JE, et al: Physical characteristics, hip flexibility and arm strength of female gymnasts classified by intensity of training across age. Sports Med 23: 95101, 1983.

19) Rowland TW: Exercise and Children's Health. Champaign, Illinois. Human Kinetics Publishing, 1990.

20) Steele VA: Injury prediction in female gymnasts. Br J Sports Med 20: 31-33, 1986.

21) Steele VA, et al: Injury amongst female gymnasts. Proceedings of the Society of Sports Sciences: Sport and Science Conference, Liverpool, 15th-17th Sept, 1983.

22) Taimela $S$, et al: Intrinsic risk factors and athletic injuries. Sports Med 9: 205-215, 1990. 